\title{
Tryptophan-like fluorescence as a fingerprint of urban river water intrusion into storm drainage system
}

Hailong Yin ( $\nabla$ yinhailong@tongji.edu.cn )

College of Environmental Science and Engineering, Tongji University https://orcid.org/0000-00024112-3731

\section{Yue Wang}

Tongji University

Yang Yang

DHI Water and Environment

Jingshui Huang

Helmholtz Center for Environmental Research

\section{Zuxin Xu}

Tongji Univeristy

\section{Research}

Keywords: storm drainage system, dry-weather misconnection, river water intrusion, fluorescence spectroscopy, Bayesian mass balance model

Posted Date: January 7th, 2020

DOI: https://doi.org/10.21203/rs.2.20179/v1

License: (c) (1) This work is licensed under a Creative Commons Attribution 4.0 International License. Read Full License

Version of Record: A version of this preprint was published at Environmental Sciences Europe on April 9th, 2020. See the published version at https://doi.org/10.1186/s12302-020-00336-3. 


\section{Tryptophan-like fluorescence as a fingerprint of urban river}

2 water intrusion into storm drainage system

4 Hailong Yin a,b,c* ${ }^{\text {, }}$ Yue Wang a,b, Yang Yang ${ }^{d}$, Jingshui Huang ${ }^{e^{*}}$, Zuxin Xu ${ }^{a, b, c}$

$6 \quad{ }^{a}$ Key Laboratory of Yangtze River Water Environment, Ministry of Education, Tongji

7 University, Shanghai, China, 200092

8 b State Key Laboratory of Pollution Control and Resource Reuse, Tongji University,

9 Shanghai, China, 200092

$10{ }^{\mathrm{c}}$ Shanghai Institute of Pollution Control and Ecological Security, Shanghai, China, 200092

$11{ }^{d}$ Danish Hydraulic Institute, Shanghai Branch, $4^{\text {th }}$ Floor,Building A, No.181 Guyi Road,

12 Shanghai, China, 200235

$13{ }^{\mathrm{e}}$ Department of Aquatic Ecosystem Analysis and Management, Helmholtz Centre for

14 Environmental Research - UFZ, Brückstraße 3a, 39114 Magdeburg, Germany

15

16 *Corresponding author. E-mail address: yinhailong@tongji.edu.cn;

17 huangjingshui@ $126 . c o m$

18

19 


\section{Abstract}

22 Inappropriate dry-weather misconnections into storm drainage system is a demanding

23 environmental problem worldwide. Especially river water intrusion into storm drains may

24 cause the overloading of storm pipes and unexpected serious dry-weather discharge. In this

25 study, we evaluated the possibility of quantifying proportional source contribution in a

26 storm drainage system with dry-weather misconnections from domestic sewage and river

27 water inflow, using rapid and low-cost fluorescence spectroscopy methods. For this

28 purpose, samples of both misconnection sources and outflows of storm drainage system

29 were collected and analyzed in a downtown catchment of Shanghai, China. Results showed

30 that fluorescent peak intensity of tryptophan-like $T_{1}$ in domestic sewage ( $802 \pm 126$ a.u.)

31 was significantly higher than that in urban river water ( $57 \pm 12$ a.u.), while fluorescent peak

32 intensities of tryptophan-like $T_{2}$ in urban river water $(998 \pm 187$ a.u.) was much higher than

33 that in domestic sewage (241 \pm 72 a.u.) due to increased phytoplankton or algal activity in

34 the polluted water. However, only Peak $T_{2}$ passed the conservative behavior test in the

35 incubation experiments, which could be used as a fingerprint for quantitatively identifying

36 the misconnections of urban river water intrusion. We further developed a Bayesian

37 fluorescence mass balance model (FMBM) to infer the percentage of dry-weather

38 misconnections into the storm drainage system as a function of fluorescence intensities of

39 Peak $T_{2}$ in the samples of sources and outflows. It was found that the maximum posteriori

40 probability estimate of the percentage of river water intrusion into the storm drains was up 
41 to $20.8 \%$ in this site, which was validated by the results of on-site investigation. Our

42 findings implied that in-situ fluorescent sensors and Bayesian FMBM for the fingerprint

43 fluorescence peak could be applied to fast track urban river water intrusion into storm

44 drainage system from both qualitative and quantitative perspective with low costs.

45 Keywords: storm drainage system, dry-weather misconnection, river water intrusion,

46 fluorescence spectroscopy, Bayesian mass balance model

\section{Background}

49 In order to mitigate overflow pollution of combined sewer systems, separate stormwater

50 system has been introduced since the 1970s, which is designed to delivers clean rain or

51 storm water to the surface water system only [1]. However, the stormwater outfalls can

52 become polluted, for example, when foul water outlets from residential or industrial

53 premises are inappropriately connected to storm water system [2-5]. Such phenomenon

54 leads to the release of untreated sewage into receiving waters, inducing urban water

55 pollution. Additionally, there is also unexpected river water intrusion into storm drains,

56 placing increased burdens on conveyance and the following hydraulic overloading of storm

57 pipe network. This may trigger the storm pumps operation on dry-weather days and result

58 in more serious urban river pollution, e.g., river's black and odorous occurrence [6-7].

59 Given the mixed surface water and sewage water inputs, there will inevitably be difficulties

60 in specifically distinguishing between misconnection-derived sewage and surface water

61 sources, when monitoring and analyzing a storm drain outfall.

62 Use of chemical tracers is a promising method to detect misconnected source flow 
63 contributions into storm drains. Specifically more and more researchers have shed light on

64 chemical or biological marker species to identify and quantify sewage source discharge.

65 For example, many researchers demonstrated that PPCPs, artificial sweeteners and

66 inorganic ions such as potassium, chloride and sodium, could serve as promising markers

67 of sewage contamination [8-16]. However, no published literatures were found concerning

68 the use of markers in identifying surface water intrusion into the storm pipes. Additionally,

69 current use of above chemical or biological markers is still less easily automated for higher

70 throughputs especially in a catchment-scale condition assessment.

71 Compared with the chemically and biologically based analytical methods, fluorescence

72 spectroscopy has the advantages of high sensitivity, simple measurement, fast analysis, low

73 sample size request and no secondary pollution, which provides both qualitative and

74 quantitative information of dissolved organic matter (DOM) in natural and engineered

75 systems [17-20]. Three-dimensional excitation-emission (EEM) fluorescence, has been

76 widely used to quantitatively characterize DOM and to follow its dynamics in different

77 aquatic environments, e.g., in rivers [21-25], estuaries or seawaters [26-28], lakes [29-32],

78 wastewater effluents [33] and groundwater [34]. Such studies concluded that fluorescence

79 characteristics of DOM varied in different water bodies. Thus, by examining them, it is

80 possible to distinguish different sources of DOM and determine the presence of different

81 sources in water bodies of concern.

82 In urbanized areas, while an increasing number of studies had characterized and traced

83 the sources of DOM using fluorescence spectroscopy to explore the influences of urban

84 landscapes and environmental factors on the urban waterbodies, few related studies

85 focused on the DOM fluorescence characterization of sewer overflows, a fact that may be 
86 ascribed to the complexity of wet-weather and dry-weather pollutants. Chen et al. [35]

87 investigated the changes of the wet-weather flow DOM characteristics and yields in

88 response to the anthropogenic influences of paved runoff and sanitary sewage inputs.

89 However, no published literatures were found regarding the dry-weather misconnections

90 into storm drainage system, a phenomenon arising from the complexity of mixed non-storm

91 water flow inputs.

92 The aim of this study was to qualitatively and quantitatively identify contributions from

93 different sources of dry-weather misconnections into storm drainage system using

94 fluorescence detection. The derived outcomes are expected to inform a methodology that

95 can be directly applied to fast diagnose the in situ dry-weather misconnections, especially

96 for the quantification of surface water intrusion into the storm drains.

98 Materials and methods

99 Site description

100 The study site is a typical high-density urbanized area (approximate $270 \mathrm{capital} / \mathrm{ha}$ ) in

101 Shanghai's downtown area, surrounded by three tidal rivers (i.e., the Puhuitang,

102 Shang' aotang and Caohejing river) (Fig. 1). Covering 374 ha, this area is served by separate

103 sewer and storm drainage system that was built in 1980s. There is only one terminal outfall

104 for the storm drainage system, where a storm pump station has been constructed to convey

105 the surface road runoff in wet-weather days to the receiving waters. However, non-storm

106 water flows including domestic sewage as well as surface water also find their ways into 107 storm drains.

108 On-site investigation showed that there were potential 99 misconnections between river 
109 and storm drains in this catchment [6]. On dry-weather days, when surface water level is

110 higher than the water level of terminal outfall (i.e., during high tide of the surrounding tidal

111 rivers), river water intrusion into storm drains occurs and may even trigger storm pumps

112 operation, delivering untreated sewage into the nearby rivers.

113

114

115

\section{On-site sampling methods}

117 Sampling activities were conducted during $16^{\text {th }}$ November, 2011 to $31^{\text {st }}$ January, 2013. For

118 the potential misconnected entries as well as the dry-weather catchment outflow, sampling

119 methods were described as below.

120 Sampling of domestic sewage. Sewage samples were collected from the sewer outlet of

121 one residential community, which was inappropriately connected to the storm drain (see

122 Fig.1). An automatic sampler (ISCO 6712C, Teledyne, Lincoln, Nebraska, USA) was used 
123 to collect the water sample by choosing the "1-h equal interval sampling" program, and 24

$124 \mathrm{~h}$ was set as a sampling cycle. The mixture of the 24 water samples was used for each

125 sampling activity. All together 18 sampling activities were conducted and correspondingly

12618 composite sewage samples were obtained.

127 Sampling of river water. The river water sampling sites were located in the three tidal

128 rivers surrounding this catchment, i.e., Puhuitang, Shang'aotang, and Caohejing rivers,

129 where six sampling sites were selected (see Fig.1). At each sampling site, water samples

130 were collected $0.5 \mathrm{~m}$ below the water surface in the midstream of the watercourse. For each

131 sampling event, one river water sample was collected at each monitoring station. Totally

13215 sampling activities were performed and 90 river water samples were obtained.

133 Sampling of catchment outflow. For the catchment outflow, the antecedent dry weather

134 period of $48 \mathrm{~h}$ was chosen before the start of each sampling campaign. Therefore, the

135 contribution of potential storm water runoff to the catchment outflow could be excluded.

136 Water samples were extracted from the terminal wet well using an ISCO 6712 automatic

137 field sampler. Like the sewage samples, outflow samples were collected every hour by

138 choosing the "1-h equal interval sampling" program, and 24 samples were obtained within

139 each day. Finally, the mixture of 24 water samples was used for the experiment analysis

140 for each sampling activity. Totally 12 sampling activities were performed.

141 All of the collected water samples were stored in the pre-washed and dried sampling

142 bottles. After being transported to the laboratory, the samples were immediately filtered

143 through a $0.45-\mu \mathrm{m}$ microporous membrane. The filtered samples were stored at $4^{\circ} \mathrm{C}$ in the

144 dark before analysis. The measurements were completed within 48 hours. 


\section{Analytical methods}

147 Fluorescence detection was carried out using Hitachi three-dimensional fluorescence 148 spectrophotometer F-4600. Each sample was placed into a 1-cm quartz cuvette for 149 detection and blank corrected. The scanning parameters were set as follows: the 150 photomultiplier tube (PMT) voltage was $700 \mathrm{~V}$, and the scanning speed was 12000 $151 \mathrm{~nm} \cdot \mathrm{min}^{-1}$. The ranges of excitation wavelength (Ex) and emission wavelength (Em) was $152 \quad 200-450 \mathrm{~nm}$ and 250-550 $\mathrm{nm}$ respectively, with the step size of $5 \mathrm{~nm}$.

153 Several post-acquisition steps were used to adjust the EEM data. First, the excitation and 154 emission data were corrected for instrument-specific response. Second, the EEM response 155 of ultrapure water was subtracted from sample EEMs. Third, the UV-visible absorption 156 spectra were used to correct the EEM data for inner filter effects.

157 Peak-picking is a viable analysis technique used for the development and use of a real158 time tool, which can be directly tied to custom sensors available today $[19,22,33,36]$.

159 Commonly there are four kinds of fluorescence peaks observed in freshwater aquatic

160 samples. These have been classified as follows: Peak A - fulvic-like $\left(\lambda_{\mathrm{ex} / \mathrm{em}}=237-260 / 400-\right.$ $161500 \mathrm{~nm})$; Peak $\mathrm{C}-$ humic-like $\left(\lambda_{\mathrm{ex} / \mathrm{em}}=300-370 / 400-500 \mathrm{~nm}\right)$; Peak $\mathrm{T}_{1}-$ tryptophan-like $162\left(\lambda_{\mathrm{ex} / \mathrm{em}}=275 / 340-350 \mathrm{~nm}\right)$ and Peak $\mathrm{T}_{2}-$ tryptophan-like $\left(\lambda_{\mathrm{ex} / \mathrm{em}}=225-237 / 340-381 \mathrm{~nm}\right)$; 163 Peak $B_{1}$ - tyrosine-like $\left(\lambda_{\text {ex/em }}=275 / 300-305 \mathrm{~nm}\right)$ and Peak $B_{2}-$ tyrosine-like $\left(\lambda_{\text {ex/em }}=225\right.$ 164 237/309-321 nm). The Peak C fluorescence can be further divided into two fluorescence 165 centres in highly coloured, peaty waters. Specifically, fluorescence is reported to occur at $166 \lambda_{\text {ex/em }}=320-340 / 410-430 \mathrm{~nm}$ and at $\lambda_{\mathrm{ex} / \mathrm{em}}=370-390 / 460-480 \mathrm{~nm}$, which are referred to as 167 Peak $\mathrm{C}_{1}$ and $\mathrm{C}_{2}$ respectively. 
170 Besides on-site sampling to detect fluorescence components of the study site, in order to

171 determine the conservative behavior or not of the detected DOM fluorescence, lab 172 experiments were also conducted.

173 Usually storm drains are designed to accommodate urban surface runoff, which means

174 they are often oversized for dry-weather flow inappropriately entering the storm pipes.

175 Therefore, the dry-weather flowing velocity within the storm drains would be very low. In

176 this catchment, it was estimated that dry-weather water flowing velocity was below 0.1

$177 \mathrm{~m} / \mathrm{s}$; correspondingly, the maximum travel time of dry-weather flow (e.g., sewage or river

178 water) within the storm network was about $24 \mathrm{hrs}$ [37]. In order to simulate the actual

179 environment in the sewer, a continuous darkroom anaerobic condition for more than 24

180 hours was used in the laboratory incubation experiment. Specifically, sewage or river water

181 samples were respectively injected into a series of $250 \mathrm{~mL}$ borosilicate glass bottles, which

182 were sealed with parafilm and wrapped with foil to represent anoxic and dark environment.

183 For each experiment, the duration was equal or greater than $24 \mathrm{hrs}$. The fluorescence was

184 measured before the experiment and at 24-h interval during the incubation experiment.

185 The experiments were performed both in the spring and winter seasons to determine the

186 effect of environmental temperature and associated microbial activities on the conservative

187 behavior of detected DOM components. In details, the incubation experiments were 188 conducted for the collected sewage samples in May, 2012 (i.e., the period of spring season)

189 and January, 2013 (i.e., the period of winter season). The experiment temperatures were

190 controlled close to the environment temperatures in the two seasons, namely with $25^{\circ} \mathrm{C}$ for

191 the incubation experiment in May and $5^{\circ} \mathrm{C}$ for the one in January. 
193 Hudson et al. pointed out that fluorescence intensities of the peaks in the specific regions

194 of the EEM could correspond to the concentrations of the compounds represented by the

195 peaks [38]. Goldman et al. further found a linear response in fluorescence peak intensity of

196 individual peaks (e.g., Peaks A, T and C) for the mixture of different source flows [22]. In

197 accordance with these criteria, for a fluorescent component exhibiting conservative

198 behavior, i.e., no obvious chemical or biological degradation within the storm drains, the

199 fluorescence mass balance equation can be written as:

$$
F_{\text {river }} \times Q_{\text {river }}+F_{\text {sewage }} \times Q_{\text {sewage }}=F_{\text {outflow }} \times Q_{\text {outflow }}
$$

200 where $F_{\text {river }}$ is the fluorescence intensity of the peak for river water samples; $Q_{\text {river }}$ is the

201 flow rate of river water intrusion into the storm drains; $F_{\text {sewage }}$ is the fluorescence intensity

202 of the peak for domestic sewage samples, $Q_{\text {sewage }}$ is the flow rate of domestic sewage

203 misconnected into the storm drains; $F_{\text {outflow }}$ is the fluorescence intensity of the peak for

204 catchment outflows; $Q_{\text {outflow }}$ is the flow rate of the storm drain outfall on dry-weather days.

205 Assuming that the percentage share of river water intrusion into the storm drains on dry-

206 weather days is $r(\%)$, the following formula could be derived from the above mass balance

207 model as:

$$
\begin{gathered}
F_{\text {river }} \times Q_{\text {outflow }} \times \mathrm{r}+F_{\text {sewage }} \times Q_{\text {outflow }} \times(1-r) \\
=F_{\text {outflow }} \times Q_{\text {outflow }}
\end{gathered}
$$

208 Divided by $Q_{\text {outflow, }}$ the model of fluorescence intensities and the percentage share of 209 river water intrusion into the storm drains can be generated as: 


$$
F_{\text {sewage }}+r \times\left(F_{\text {river }}-F_{\text {sewage }}\right)=F_{\text {outflow }}
$$

210 A Bayesian method was employed here to infer $r$, which is capable of accounting for the

211 measurement errors of fluorescence intensities and estimate the uncertainty of the

212 percentage share [39]. A widely used Markov Chain Monte Carlo (MCMC) approach was

213 integrated with the model using DREAM [40]. Normal distribution tests were performed

214 with the measurements of $F_{\text {river, }} F_{\text {sewage }}$ and $F_{\text {outflow }}$ to obtain the means and standard

215 deviations of their distributions, respectively. $F_{\text {river, }}, F_{\text {sewage }}$ and $r$ were defined as the input

216 parameters in the model. The prior information of $F_{\text {river }}$ and $F_{\text {sewage }}$ was provided by the

217 estimates of their normal distribution parameters, respectively. A uniform probability

218 density function (PDF) between 0 and 1 was considered for the prior distribution of $r$.

$219 F_{\text {outflow }}$ is defined as the output of the model. The model parameter inferences were based

220 on the log-likelihood function:

$$
\log L=-\frac{M}{2} \log (2 \pi)-\sum_{i=1}^{M} \log \sigma_{i}-\frac{1}{2} \sum_{i=1}^{M} \frac{1}{\sigma_{i}{ }^{2}}\left(F_{i}^{o b s}-F_{i}^{s i m}\right)^{2}
$$

221 where $i$ and $M$ donate the $i^{\text {th }}$ measurement and the number of measurements,

222 respectively; $F^{\text {obs }}$ and $F^{\text {sim }}$ are observed and simulated $F_{\text {outflow, }}$ respectively; $\sigma$ denotes the

223 standard deviation of the Gaussian distribution of observed $F_{\text {outflow. }}$

\section{Results and Discussion}

226 The EEMs from samples collected from the domestic raw sewage and urban river water

227 have been evaluated and show 3 peaks $\left(T_{1}, T_{2}, B_{1}\right)$ with the strongest fluorescence 228 intensities (Fig.2). More information concerning the EEM spectra of these samples 
229 collected was listed in Supporting Information S1 and S2 for domestic sewage and river

230 water respectively.

231
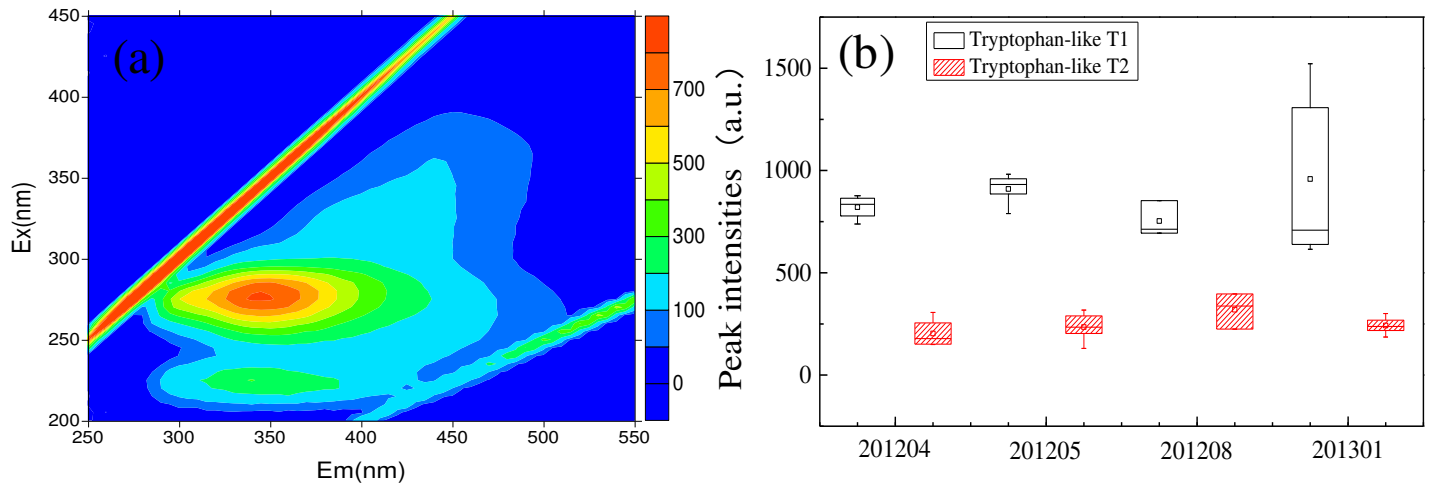

232
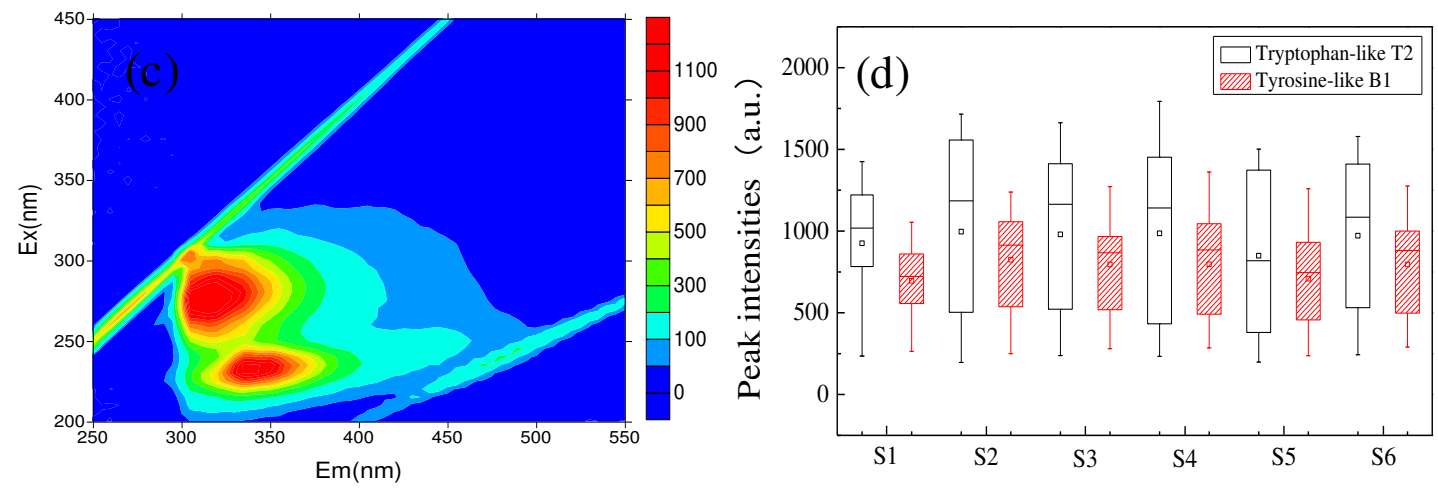

233 Fig.2 Detected EEMs for the domestic sewage and urban river water samples: (a) typical

234 EEM of untreated domestic sewage; (b) fluorescent peak intensities of domestic sewage

235 samples; (c) typical EEM of urban river water; (d) fluorescent peak intensities of urban

236 river water at six sampling stations.

238 EEM characteristics of domestic sewage

239 Fig.2(a) showed that basically there were two main fluorophores in the spectrum of

240 domestic sewage. The first fluorescence intensity peak was at Ex/Em of 275/350 nm, which

241 corresponded to tryptophan-like peak $\mathrm{T}_{1}$ components. The second fluorescence intensity

242 peak was at Ex/Em of $225 / 350 \mathrm{~nm}$, which was associated with tryptophan $\mathrm{T}_{2}$ fluorescent 
243 components. The detected tryptophan-like fluorescent components are mainly protein-like

244 substances, which may be derived from the human activities such as human excreta, food

245 residues and cooking oils [41]. In addition, a distinct narrow band occurred at $\lambda_{\mathrm{ex}}=330$ -

$246375 \mathrm{~nm}$ for $\lambda_{\mathrm{em}}=410-450 \mathrm{~nm}$. This is can be explained by the fluorescent whitening agents

247 from the grey water such as dishes and clothes washing, which also indicates the

248 contribution of the domestic sewage to some extent. Considering domestic sewage is

249 transported through pipelines and has no direct contact with soil, the possibility of humus

250 from the soils is small. Therefore, the humic-like fluorescent components in domestic

251 sewage are mainly derived from the humic acids originated in tap water supply. From this

252 perspective, the intensity of humic-like substances were much less pronounced than the

253 protein-like ones in the domestic raw sewage samples.

254 Based on Fig.2(b), the averaged fluorescent peak intensity of tryptophan-like $\mathrm{T}_{1}$ and 255 tryptophan-like $T_{2}$ material were 865 a.u. and 256 a.u respectively, with an average $T_{1} / T_{2}$

256 ratio of 3.4. Hudson et al. [17] observed an approximate $T_{1} / T_{2}$ ratio of 3.0 for samples

257 collected from sewage effluents, close to the data from our study. In Fig.2(b), increased

258 fluorescent peak data for $\mathrm{T}_{1}$ was associated with organic matter of oils. For example, real-

259 time fluorescent peak data in a small urban river recorded by Carstea et al. [19], showed

260 that the fluorescent ratio between $\mathrm{T}_{1}$ and $\mathrm{T}_{2}$ rose to $4 \sim 5$ from previous 1.7 3.5 during the

261 diesel pollution. Chen et al. [41] presented the $T_{1} / T_{2}$ ratio of soybean oil was 3.8 , whereas

262 in bovine serum albumin (i.e., a standard substance in protein quantitation) the data was

263 only 1.0. Therefore, peak $T_{1}$ is identified as being most likely to be the signature of

264 domestic sewage. 


\section{EEM characteristics of river water}

267 As indicated in Fig.2(c), there were two distinct fluorescence peaks in the EEMs of the

268 river water samples, with the Ex/Em at 230/340 nm and 275/305 nm respectively. The peak

269 at EEM of 230/340 $\mathrm{nm}$ corresponds to tryptophan-like $\mathrm{T}_{2}$ materials, and the peak at EEM

270 of $275 / 305 \mathrm{~nm}$ corresponds to tyrosine-like $\mathrm{B}_{1}$ materials. Both the tryptophan-like $\mathrm{T}_{2}$ and

271 tyrosine-like $\mathrm{B}_{1}$ belong to protein-like materials.

272 As for the humic or fulvic substance, a fluorophore was also generated at with the Ex/Em

273 at $250 / 435-455 \mathrm{~nm}$. However, its fluorescence intensity was not as high as that of

274 tryptophan-like $T_{2}$ and tyrosine-like $B_{1}$ substances in this case. Previous studies by Hudson

275 et al. [38] showed that in clean rivers, Peaks $\mathrm{C}_{1}, \mathrm{C}_{2}$ and A predominate. This is because

276 DOM originating from clean river water is dominated by natural organic matter from plant

277 material whereas sewage-derived DOM is dominated by organic matter originating from

278 microbial activity. By contrast, our study showed that tryptophan-like or tyrosine-like

279 substances, instead of humic-like or fulvic-like substances, are the indication of polluted

280 urban river water. Therefore, with increasing urbanization and anthropogenic activities, the

281 fluorescent signature of urban waters changed with increasing human impact from humic-

282 rich to protein-rich with Peaks T and B.

283 Fig.2(d) further showed the measured fluorescent peak intensities of urban river water

284 at six sampling stations. Among the six sites, the S1 monitoring site is located in

285 Shang'aotang River, where sluice gates are installed (see Fig.1). As a result, Shang'aotang

286 River is separated from other rivers including Puhuitang River and Caohejing River, which

287 are polluted by the dry-weather as well as wet-weather outflow from the storm drains of

288 this catchment. By contrast, no storm drains outfalls are directly connected to the 
289 Shang'aotang River. Therefore, water quality at S1 station was better than that of the other

290 five sampling stations. However, the fluorescence intensities of tryptophan-like $T_{2}$ and

291 tyrosine-like $\mathrm{B}_{1}$ at the $\mathrm{S} 1$ station were not considerably different from those at other five

292 stations. This showed that fluorescence property of urban polluted rivers was determined

293 by materials more than sewage-derived DOMs.

294 Differences of EEM characteristics between domestic sewage and urban river water

295 Our study showed that domestic sewage featured most strongly tryptophan-like Peaks $T_{1}$

296 and $\mathrm{T}_{2}$, whereas urban river water featured tryptophan-like Peak $\mathrm{T}_{2}$ and tyrosine-like Peak

$297 B_{1}$. Both domestic sewage and urban river water are characteristics of tryptophan-like $T_{2}$

298 fluorescence; however, it was interesting that tryptophan-like Peak $T_{2}$ in the urban river

299 water was more intense than that in the untreated domestic sewage.

300 Fig.3 showed that organic matter in the investigated urban rivers exhibited seasonally

301 different fluorescence intensities over the sampling period. Tryptophan-like Peak $\mathrm{T}_{2}$ as well

302 as tyrosine-like Peak $\mathrm{B}_{1}$ was observed to be more intense in winter as compared to that in

303 summer. This was related to elevated river water levels due to stormwater runoff discharge

304 into rivers and resulting dilution effect in summer to some extent. However, even diluted

305 by stormwater runoff, fluorescence intensities in Peaks T and B of river water samples were

306 still higher than those of sewage samples. The explanation is Peaks T and B are related to

307 microbial activity [42] and may be transported into a system (allochthonous) or be created

308 by microbial and biological activity within a system (autochthonous). Intensive

309 tryptophan-like $\mathrm{T}_{2}$ and tyrosine-like $\mathrm{B}_{1}$ are related to biological activity particularly in

310 areas of high primary productivity, that is, surface waters with phytoplankton or algal

311 activity. Under this circumstance, tryptophan-like $\mathrm{T}_{2}$ and tyrosine-like $\mathrm{B}_{1}$ fluorescence may 
312 be present as 'free' molecules or else bound in proteins or humic structurers of algae cells

313 and their remnants in river waters. In Shanghai area, majority of aquatic plants grow in the

314 spring and summer season and decay in the winter season [43]. Decomposition of aquatic

315 plants contributed to the intensified tryptophan-like $\mathrm{T}_{2}$ and tyrosine-like $\mathrm{B}_{1}$ substances.

316 Such explanation could be strengthened by recently reported protein-like fluorescence in

317 Taihu Lake, China, where the tryptophan-like components of DOM were significantly

318 higher in winter than in summer and autumn, due to the degradation of phytoplankton [32].

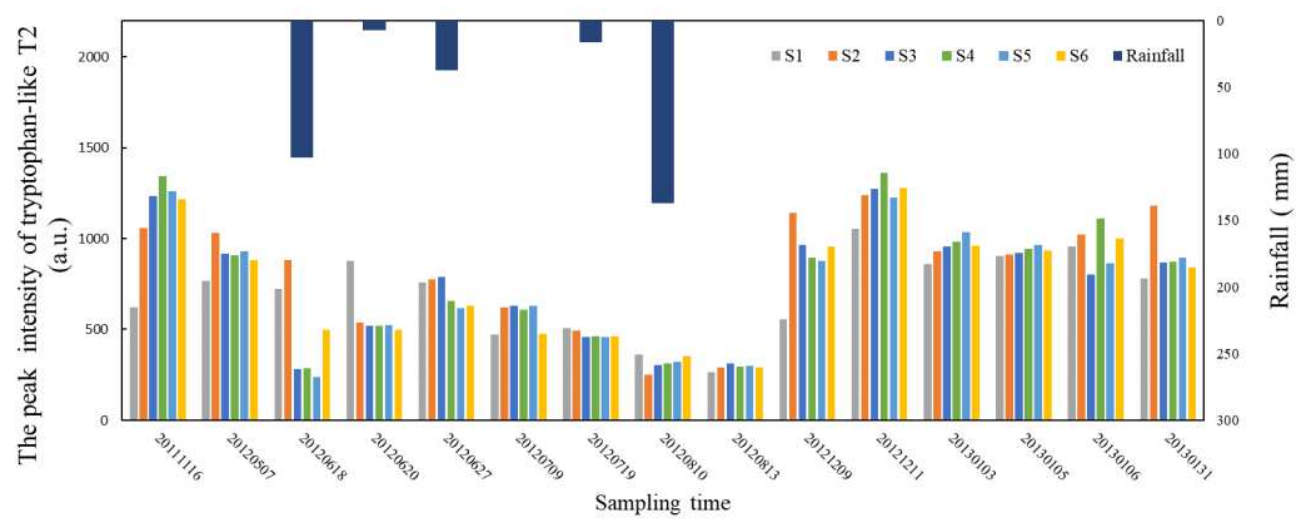

319

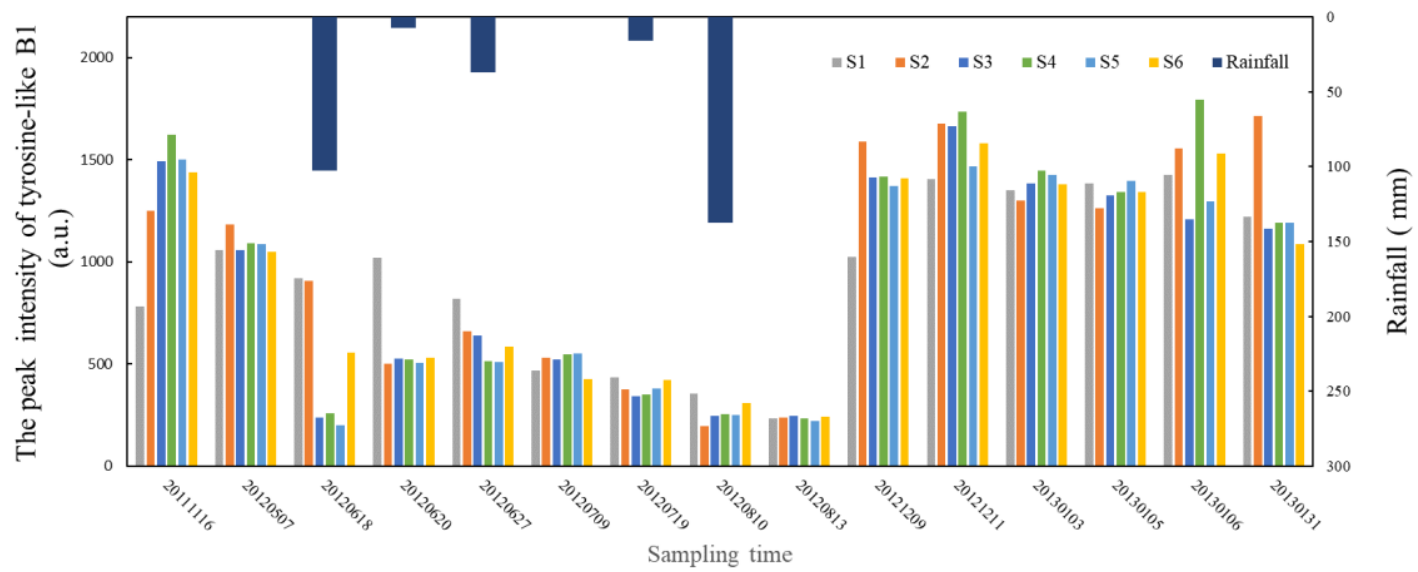

Fig.3 Detected fluorescence intensities at six sampling sites of the urban river water.

323 Another explanation is as follows. Usually, at lower water temperature, dinoflagellate or

324 diatom are predominant algal species; by contrast, at higher water temperature, green algae 
325 and blue algae take the lead in algal growth. Among the algal species, dinoflagellate and

326 diatom are dominant producers of terrestrial sources, featuring higher contents of

327 tryptophan-like and tyrosine-like materials than those in green and blue algae. Moreover,

328 there is a good correlation between Peaks T and B materials produced by algal species of

329 dinoflagellate and diatom [44], as proved by in this study. In this case, a strong liner

330 relationship between the fluorescence peak intensities of tryptophan-like $\mathrm{T}_{1}$ and tyrosine-

331 like $\mathrm{B}_{1}$ was demonstrated, with average correlation coefficient of $0.96(\mathrm{p}<0.01)$.

332 Based on above discussions, higher $\mathrm{T}_{2}$ fluorescence intensity observed in the urban

333 river water was due to phytoplankton or algal related activity in the polluted urban river.

334 Specifically, if excluding the river fluorescent data disturbed by stormwater runoff in

335 sampling period of summer season, average $\mathrm{T}_{2}$ peak intensity in urban river water samples

336 was 998 a.u., but average $\mathrm{T}_{2}$ peak intensity in untreated domestic sewage was only 241 a.u..

337 The intensities in Peak $T_{2}$ between urban river water and domestic sewage differed by 4.1

338 times. This revealed that tryptophan-like Peak $\mathrm{T}_{2}$ would be of great potential for the use in

339 indicating the urban river water and associated river water intrusion into urban drainage

340 system.

341 Conservative behaviour of fluorescence peaks in sewage and surface water

342 Changes in observed fluorescence peak intensities of domestic sewage and river water

343 samples during the experiments were shown in Fig.4 and Supporting Information S3. As

344 seen in Fig.4(a) and Fig.4(b), for the domestic sewage samples, lab incubation experiments

345 conducted in May showed fluorescence peak intensities of tryptophan-like $\mathrm{T}_{1}$ and tyrosine-

346 like $\mathrm{B}_{1}$ decreased over time rapidly with the experimental duration. Fluorescence intensity

347 of Peak $\mathrm{T}_{1}$ and $\mathrm{B}_{1}$ decreased by $70.8 \%$ and $66.1 \%$ respectively on average after $24 \mathrm{hrs}$. In 
348 this process, fluorescence intensities of other fluorescent components did not increase

349 correspondingly (see Supporting Information S3). This result indicated that the

350 fluorescence intensities of the tryptophan-like $T_{1}$ and tyrosine-like $B_{1}$ substances converted

351 into non-fluorescent substances with time. As discussed above, the tryptophan-like $\mathrm{T}_{1}$ and

352 tyrosine-like $\mathrm{B}_{1}$ component in domestic sewage were considered to be microbial by-

353 products, and therefore changes in their fluorescence intensities were related to microbial

354 metabolism. For this scenario under the lab temperature of $25^{\circ} \mathrm{C}$, active microbial activity

355 dramatically degraded their fluorescent substances. Reynolds concluded that microbial

356 activity, measured by oxygen depletion in the $\mathrm{BOD}_{5}$ test, correlates well with the $\mathrm{T}_{1}$

357 fluorescence intensity of raw sewage [45]. Therefore $T_{1}$ is presented in a bioavailable

358 substrate. However, for the incubation experiments conducted in January, the fluorescence

359 signature of tryptophan-like $\mathrm{T}_{1}$ and tyrosine-like $\mathrm{B}_{1}$ component in domestic sewage almost

360 remained unchanged with time. This can be explained by inhibited microbial activity under

361 lower lab temperature (e.g., the temperature of $5^{\circ} \mathrm{C}$ ), leading to relatively stable

362 fluorescence peak intensities.

363 Changes of fluorescence signature of tryptophan-like $\mathrm{T}_{2}$ with experimental duration was

364 shown in Fig.4(c) and Fig.4(d) for domestic sewage and surface water samples. For the

365 domestic sewage samples, unlike tryptophan-like $T_{1}$ and tyrosine-like $B_{1}$ substance,

366 tryptophan-like $\mathrm{T}_{2}$ exhibited conservative behavior, independent of environmental

367 temperature. The explanation may be that tryptophan-like $T_{2}$ substance contains more

368 simple aromatic structurers, which are less likely to be degraded. Our experimental results

369 further strengthened that tryptophan-like $\mathrm{T}_{2}$ component could be associated with

370 biodegradation of wastewater, i.e., they could be the bio-refractory organics or microbial 
371 byproducts [23]. Similar results were found in experiments of river water samples, in which

372 fluorescence intensities in tryptophan-like $T_{2}$ substance also didn't change within the

373 experimental duration of 72 hours. However, while tryptophan-like $\mathrm{T}_{2}$ component in raw

374 sewage could be cited as anthropogenically derived organics, $T_{2}$ component in surface

375 water is believed to be belonging to plankton-derived organics. Especially, there could be

376 higher levels of non-biodegradable organics in urban river than those in untreated domestic

377 sewage.

378
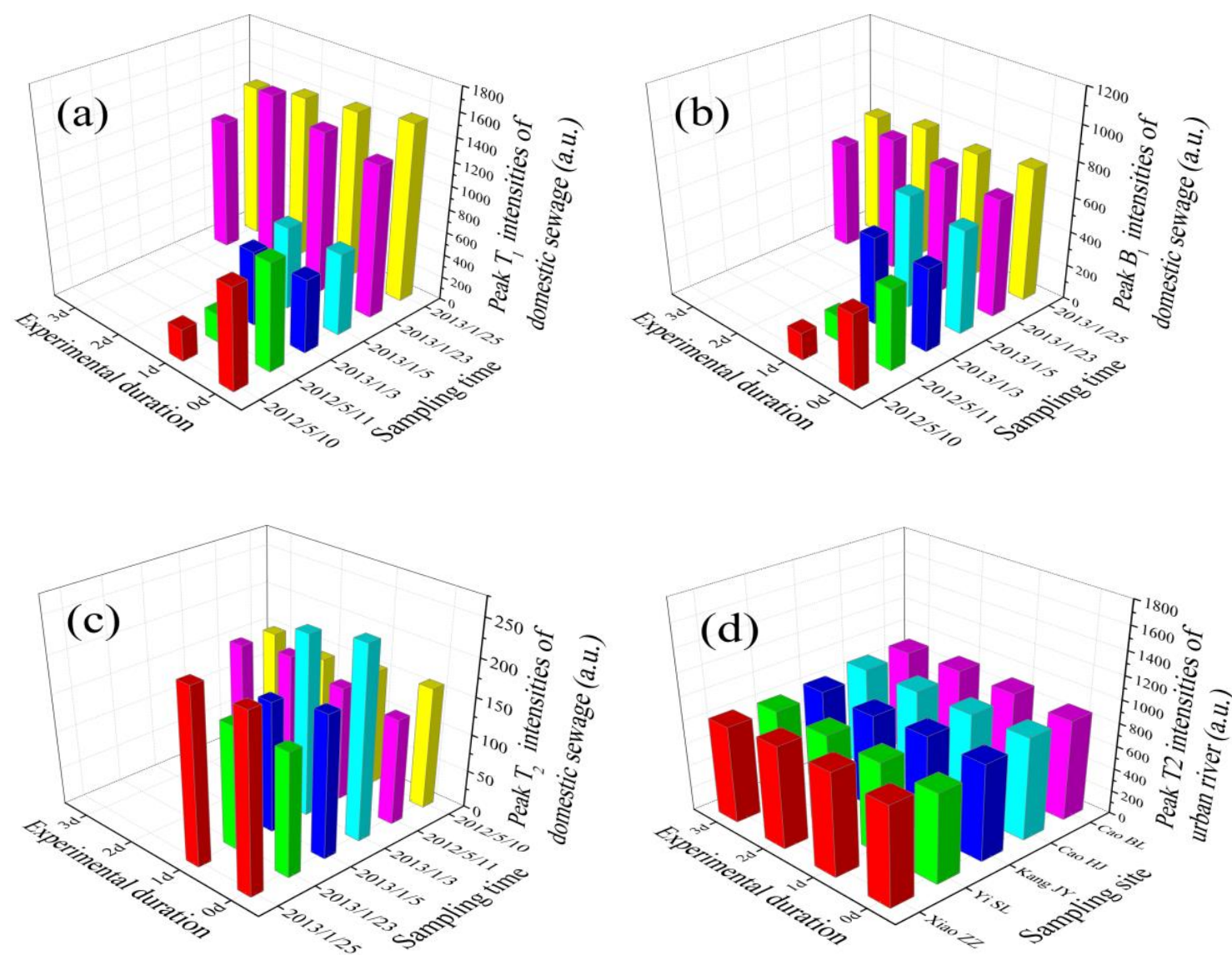

379

380 Fig.4 Changes of fluorescence peak intensities of domestic sewage and urban river water

381 samples within the experimental duration. 
384 Based on above discussion, tryptophan-like $\mathrm{T}_{2}$ can be used as an ideal marker to quantify

385 percent wastewater and urban river water with inappropriate entry into storm drains on dry-

386 weather days, which features conservative characteristics in both of the two misconnected

387 source types. Thus, the uncertainty of fluorescence mass balance model arising from

388 chemical or biological reaction within the storm pipes could be minimized as possible as

389 can.

390 Determination of percent surface water and wastewater into the storm drains

391 To determine the percent surface water into storm drains, the fluorescence mass balance

392 model was set up for fluorescence Peak $T_{2}$ with its fluorescence intensity measurements of

393 the samples from the river water, domestic sewage and catchment outlet. Comparison of

394 fluorescence Peak $T_{2}$ among domestic sewage, river water and catchment outflow was

395 presented in Fig.5. More information concerning detected EEMs for all of the catchment

396 outflow samples were provided in Supporting Information S4.

397 As seen in Fig.5, for both summer and winter season periods, the fluorescence Peak $\mathrm{T}_{2}$

398 intensities in the catchment outflows were higher than those in the domestic sewage, due

399 to occurrence of river water intrusion. For catchment outflow, generally fluorescence

400 intensities of tryptophan-like $T_{2}$ in winter were higher than that in summer, as a result of

401 intensified fluorescence Peak $T_{2}$ of river water in the winter season period. Therefore,

402 fluorescence spectrometry has the promise for indicating the presence of river water

403 intrusion into storm drains as a rapid, reagentless technique that requires little sample

404 preparation. 


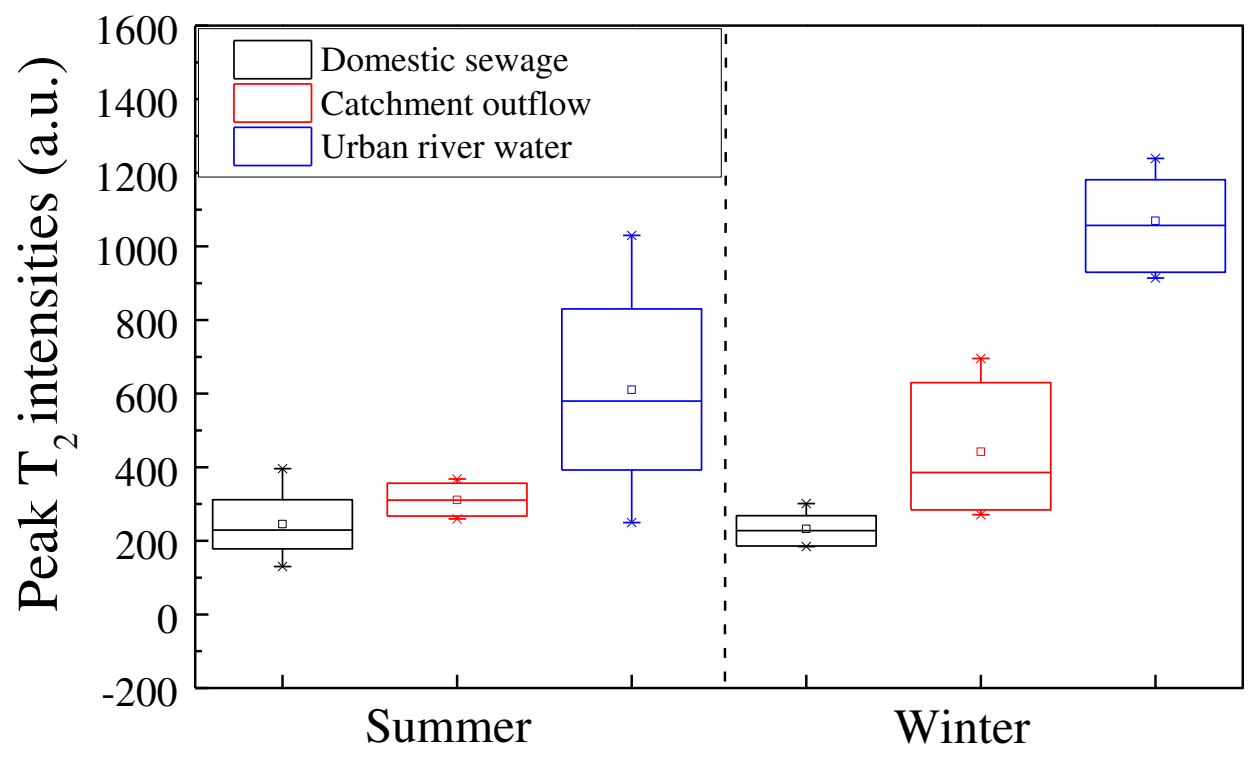

406 Fig.5. Comparison of fluorescence peak $\mathrm{T}_{2}$ intensities for the samples among river water,

407 domestic sewage and catchment outflow.

409 The Bayesian inference results of the percent river water into the storm drains for the 410 two season periods were shown in Fig.6. It showed that the maximum a posteriori 411 probability (MAP) estimate of the percent is $12.7 \%$ and $20.8 \%$ in summer season and 412 winter season respectively. Theoretically, the amount of river water backflow is determined 413 by the pressure head between surface water and storm drains; the higher the river water 414 level, the larger the amount of river water backflow. Therefore, higher MAP in winter was 415 associated with lower water level of storm drains of non-flood season period. However, 416 uncertainty of Bayesian result in summer was higher than that in winter. This is possibly 417 due to frequent rainfall events and intense precipitation during summer season. Storm water 418 discharges led to significant variations of fluorescent substances in the three surrounding 419 rivers (see Fig.5), and the resulting increased uncertainty of percent river water intrusion. 

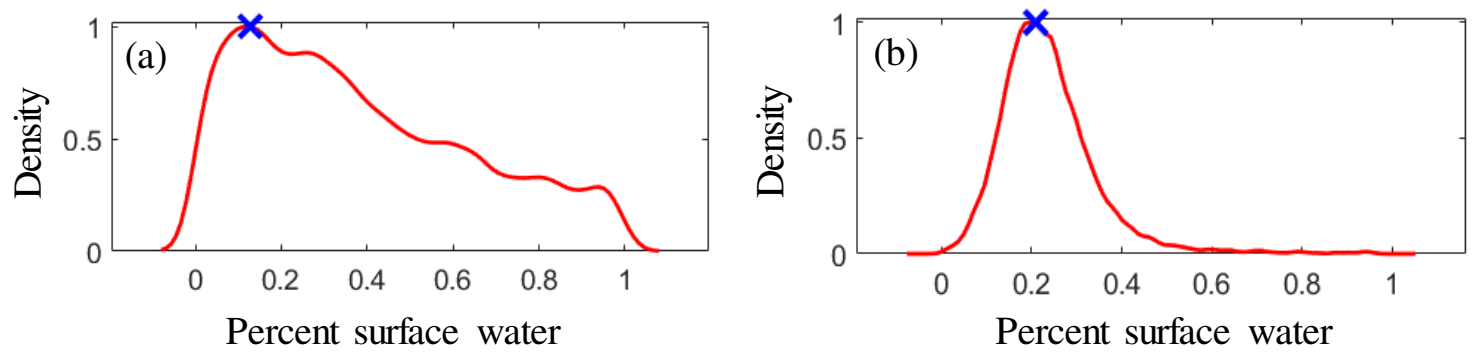

421 Fig.6 Maximum a posteriori probability (MAP) estimate for the percentage share of river

422 water backflow into the storm drains on dry-weather days: (a) summer season; (b) winter 423 season.

425 The Bayesian inference results were validated with the estimated time-series river water 426 inflow in winter season in this case. Fig. 7 showed the measured historical real-time water 427 levels between surrounding rivers and terminal outfall within one month of winter season 428 period (i.e., Dec., 2008). Using the mathematical function between river water inflow and 429 pressure head established in this catchment (i.e., Qriver $=0.104^{*} \Delta \mathrm{h}^{1 / 2}$, Q river is river water 430 inflow and $\Delta \mathrm{h}$ is the sum of real-time water pressure head between river water level and 431 terminal wet well level within one day) [6], the daily river water inflow was accordingly 432 determined, as seen in Fig.7. It was known from this figure that when storm pumps operated 433 to lower the terminal wet-well level to the lowest alarm level, the significantly increased 434 pressure head drives large amounts of river water inflow in a short period of time. For the 435 non-pumping discharge periods, river water inflow is much smaller as compared to that 436 under the pumping discharge periods. In this figure, the daily river water inflow ranged 437 from $145 \sim 11705 \mathrm{~m}^{3} / \mathrm{d}$, with an average data of $4261 \mathrm{~m}^{3} / \mathrm{d}$.

438 Our previous study showed that catchment outflow on dry-weather days was 439 approximately 19,350 21,600 $\mathrm{m}^{3} / \mathrm{d}[6]$; therefore maximum likelihood value of river water 
440 inflow in winter season was about $4025 \sim 4493 \mathrm{~m}^{3} / \mathrm{d}$ based on MAP estimate for percent

441 surface water intrusion. The daily averaged river water inflow based on Fig.7 coincided

442 well with the MAP estimate, with a relative error less than $10 \%$. This demonstrates that

443 FMBM is robust in quantifying surface water intrusion into storm drains.

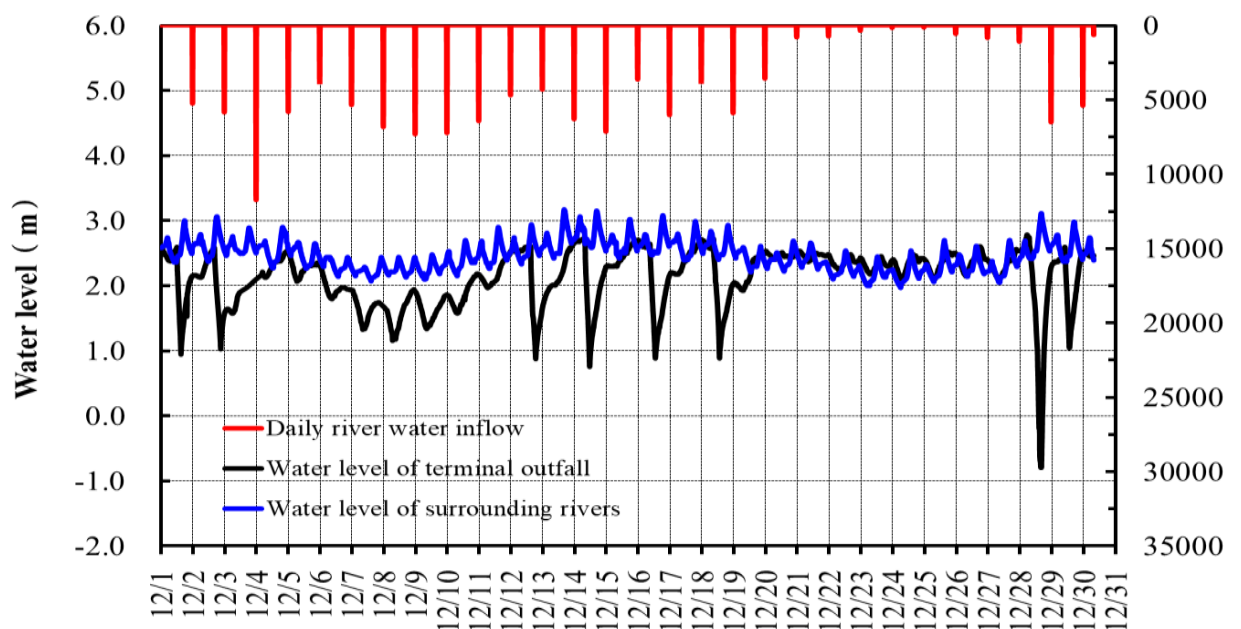

445 Fig.7 Estimated daily river water inflow into storm drains based on real-time water level

446 between river and catchment outfall in winter season period.

\section{Environmental implications}

449 The use of fluorescence to predict the presence and quantity of urban river water into a

450 storm drainage system has significant environment implications. Recent advancements in

451 sensor technology and the development of reliable and specific fluorescence probes have

452 increased our ability to monitor organic matter characteristics in near real-time. The 453 application of real-time data and fluorescence mass balance model would allow water 454 managers to track and quantify river water inflow without high costs associated with labor455 intensive investigations or complex analytical approaches. For example, establishing a 456 fitted analytical function to determine the river water inflow, has to depend on long-term 
457 real-time synchronous flow discharge and pressure head data (river water level versus

458 catchment water level) for each catchment. By contrast, if aided with tryptophan-like $\mathrm{T}_{2}$

459 sensor and FMBM introduced in this study, administrative managers would be provided

460 with a useful, fast and cheap alternative way for the investigation of dry-weather

461 misconnections into urban storm drainage system.

462 The study was conducted on polluted urban rivers, whereas there may be dissimilarities

463 in the organic matter of other surface water bodies or misconnected source types. However,

464 we can develop same approaches to identify and quantify illicit discharges, considering

465 custom sensors have already been constructed to capture the key peaks such as the strong

466 microbial fluorescence signal. Additionally, the presented fluorescence approach could be

467 combined with other chemical tracers to present an in-depth insight into illicit discharge

468 investigation of various source types from a wider perspective, and also determine the best

469 times to perform other chemical analyses if necessary.

\section{Conclusion}

471 In the present study, fluorescence spectroscopy method was used to detect and quantify

472 urban river water from the dry-weather flows that inappropriately entered into the storm

473 drains. Our findings were listed as follows.

474 The fluorescence spectra of two misconnected sources including domestic sewage and

475 urban river water exhibited substantially different characteristics, with the strongest

476 fluorescence peak centers at an excitation/emission wavelength (Ex/Em) of 275/350 nm

477 (tryptophan-like $T_{1}$ fluorescent substances) for the domestic sewage and 230/340 nm

478 (tryptophan-like $\mathrm{T}_{2}$ fluorescent substances) for the urban river water, respectively.

479 Results showed that fluorescence peak intensities of tryptophan-like $\mathrm{T}_{1}$ in domestic 
480 sewage ( $802 \pm 126$ a.u.) was significantly higher than that in urban river water (57 \pm 12 a.u.),

481 while fluorescence peak intensities of tryptophan-like $T_{2}$ in urban river water $(998 \pm 187$

482 a.u.) was much higher than that in domestic sewage ( $241 \pm 72$ a.u.). Higher $T_{2}$ fluorescence

483 intensity observed in the urban river water was associated with the increased phytoplankton

484 or algal activity in the polluted urban river.

485 Lab incubation experiments showed that only Peak $T_{2}$ passed the conservative behavior, 486 which could be used as a fingerprint for quantitatively identifying the misconnections of 487 urban river water intrusion. Using the developed Bayesian fluorescence mass balance 488 model (FMBM), the MAP estimate of the percent river water into the storm drains in a 489 downtown catchment of Shanghai, China $\left(3.74 \mathrm{~km}^{2}\right)$ can be responsible for up to $20.2 \%$.

490 This result has a relative bias less than $10 \%$ compared with the averaging values within 491 one month of winter season, derived from real-time water pressure head between river and 492 storm drainage system.

493 Our findings highlighted that the presented Bayesian FMBM approach could be 494 employed to infer the contribution of surface water intrusion into the storm drains. In the 495 future, custom sensors can be installed to real-time analyze the fingerprint fluorescence 496 peak in the storm drainage system. The application of real-time fluorescence data and 497 Bayesian FMBM method should allow urban water manager to track misconnections from 498 both qualitative and quantitative perspective without high costs and implement timely 499 response measures.

500

501 Acknowledgements

502 Not applicable. 


\section{Author's contributions}

504 All authors contributed to the study conception and design. Material preparation, data

505 collection and analysis were performed by YH, YY, HJ and XZ. The first draft of the

506 manuscript was written by $\mathrm{YH}$ and HJ. All authors commented on previous versions of the

507 manuscript. All authors red and approved the final manuscript.

\section{$508 \quad$ Funding}

509 This study was financially supported by National Natural Science Foundation of China

510 (grant no. 51979195).

\section{Availability of data and materials}

512 Not applicable.

\section{Ethics approval and consent to participate}

514 Not applicable.

\section{Consent for publication}

516 Not applicable.

\section{$517 \quad$ Competing interests}

518 The authors declare no competing financial interest.

\section{$520 \quad$ References}

521 1. Hoes OAC, Schilperoort RPS, Luxemburg WMJ et al (2009) Locating illicit connections

522 in storm water sewers using fiber-optic distributed temperature sensing. Water Research

$523 \quad 43(20): 5187-5197$

524 2. Brown E, Caraco D, Pitt R (2004) Illicit Discharge Detection and Elimination, a 525 Guidance Manual for Program Development and Technical Assessments. 378. Center 
526 for Watershed Protection, Maryland, U.S.

527 3. Irvine K, Rossi MC, Vermette S et al (2011) Illicit discharge detection and elimination:

528 low cost options for source identification and trackdown in stormwater systems. Urban

529 Water J. 8 (6):379-395

530 4. Ellis J B, Butler D (2015) Surface water sewer misconnections in England and Wales:

531 Pollution sources and impacts. Science of the total environment 526:98-109

532 5. Xu ZX, Xu J, Yin HL et al (2019) Urban river pollution control in developing countries.

$533 \quad$ Nature Sustainability 2:158-160

534 6. Xu ZX, Yin HL, Li HZ (2014) Quantification of non-stormwater flow entries into storm

535 drains using a water balance approach. Sci. Total Environ. 487:381-388

536 7. Yin HL, Lu Y, Xu ZX et al (2017) Characteristics of the overflow pollution of storm

537 drains with inappropriate sewage entry. Environmental Science and Pollution Research $538 \quad 24: 4902-4915$

539 8. Nakada N, Kiri K, Shinohara H et al (2008) Evaluation of pharmaceuticals and personal

540 care products as water-soluble molecular markers of sewage. Environ. Sci. Technol. 42

$541 \quad(17): 6347-6353$

542 9. Buerge IJ, Buser HR, Kahle M et al (2009) Ubiquitous occurrence of the artificial

543 sweetener acesulfame in the aquatic environment: an ideal chemical marker of domestic

544 wastewater in groundwater. Environ. Sci. Technol. 43 (12): $4381-4385$

545 10. Gasser G, Rona M, Voloshenko A et al (2011) Evaluation of micropollutant tracers. II.

546 Carbamazepine tracer for wastewater contamination from a nearby water recharge

$547 \quad$ system and from non-specific sources. Desalination 273 (2) :398-404

548 11. Tran NH, Hu J, Li J et al (2014) Suitability of artificial sweeteners as indicators of raw 
549 wastewater contamination in surface water and groundwater. Water Res. 48:443-456

550 12. Tran NH, Li J, Hu J et al (2014) Occurrence and suitability of pharmaceuticals and

551 personal care products as molecular markers for raw wastewater contamination in

552 surface water and groundwater. Environ. Sci. Pollut. Res. 21 (6) :4727-4740

553 13. Sun Q, Li M, Ma C et al (2016) Seasonal and spatial variations of PPCP occurrence,

554 removal and mass loading in three wastewater treatment plants located in different

555 urbanization areas in Xiamen, China. Environ. Pollut. 208 (Pt B) :371-381

556 14. Yang YY, Liu WR, Liu YS et al (2017) Suitability of pharmaceuticals and personal care

557 products (PPCPs) and artificial sweeteners (ASs) as wastewater indicators in the Pearl

558 River Delta, South China. Sci. Total Environ. 590:611-619

559 15. Xu ZX, Wang LL, Yin HL et al (2016) Source apportionment of non-storm water entries

560 into storm drains using marker species: Modeling approach and verification. Ecol. Indic.

$561 \quad 61: 546-557$

562 16. Yin HL, Xie M, Zhang LY et al (2019) Identification of sewage markers to indicate

563 sources of contamination: Low cost options for misconnected non-stormwater source

564 tracking in stormwater systems. Science of the Total Environment 648:125-134

565 17. Hudson N, Baker A, Ward D et al (2008) Can fluorescence spectrometry be used as a

566 surrogate for the Biological Oxygen Demand (BOD) test in water quality

567 assessment? An example from South West England. Science of the Total Environment

$568 \quad 391: 149-158$

569 18. Henderson RK, Baker A, Murphy KR et al (2009) Fluorescence as a potential

570 monitoring tool for recycled water systems: A review. Water Research 43:863-881

571 19. Carstea EM, Baker A, Bieroza M et al (2010) Continuous fluorescence excitation- 
572 emission matrix monitoring of river organic matter. Water Research 44:5356-5366

573 20. Yu H, Song Y, Gao $\mathrm{H}$ et al (2015) Applying fluorescence spectroscopy and

574 multivariable analysis to characterize structural composition of dissolved organic

575 matter and its correlation with water quality in an urban river. Environ. Earth Sci.

$576 \quad 73: 5163-5171$

577 21. Baker A, Inverarity R, Charlton $M$ et al (2003) Detecting river pollution using 578 fluorescence spectrophotometry: Case studies from the Ouseburn, NE England.

$579 \quad$ Environmental Pollution 124 (1):57-70

580 22. Goldman JH, Rounds SA, Needoba JA (2012) Applications of Fluorescence

581 Spectroscopy for Predicting Percent Wastewater in an Urban Stream. Environmental

$582 \quad$ Science \& Technology 46:4374-4381

583 23. Meng F, Huang G, Yang X et al (2013) Identifying the sources and fate of 584 anthropogenically impacted dissolved organic matter (DOM) in urbanized rivers. Water $585 \quad$ Research 47:5027-5039

586 24. Li S, Zhang J, Guo E et al (2017) Dynamics and ecological risk assessment of 587 chromophoric dissolved organic matter in the Yinma River Watershed: Rivers, 588 reservoirs, and urban waters. Environmental Research 158:245-254

589 25. Zhao Y, Song K, Lv L et al (2018) Relationship changes between CDOM and DOC in 590 the Songhua River affected by highly polluted tributary, Northeast China. 591 Environmental Science and Pollution Research 25:25371-25382

592 26. Coble P.G. (1996) Characterization of marine and terrestrial DOM in seawater using 593 excitation-emission matrix spectroscopy. Marine Chemistry 51(4):325-346

594 27. Baker A, Spencer RGM(2004) Characterization of dissolved organic matter from 
595 source to sea using fluorescence and absorbance spectroscopy. Science of the Total

596 Environment 333(1-3):217-232

597 28. Osburn CL, Handsel LT, Mikan MP et al (2012) Fluorescence Tracking of Dissolved

598 and Particulate Organic Matter Quality in a River-Dominated Estuary. Environ. Sci.

599 Technol.46(16):8628-8636

600 29. Zhang Y, Yin Y, Feng L et al (2011) Characterizing chromophoric dissolved organic

601 matter in Lake Tianmuhu and its catchment basin using excitation-emission matrix

602 fluorescence and parallel factor analysis. Water Research 45(16):5110-5122

603 30.Yao X, Zhang Y, Zhu G et al (2011) Resolving the variability of CDOM fluorescence in

$604 \quad$ Lake Taihu and its tributaries. Chemosphere 82:145-155

605 31. Song F, Wu F, Feng W et al (2019) Depth-dependent variations of dissolved organic

606 matter composition and humification in a plateau lake using fluorescence spectroscopy.

607 Chemosphere 225:507-516

608 32. Lü WW, Yao X, Shao KQ et al (2019) Unraveling the sources and fluorescence

609 compositions of dissolved and particulate organic matter (DOM and POM) in Lake

610 Taihu, China. Environmental Science and Pollution Research 26:4027-4040

611 33. Henderson RK, Baker A, Murphy KR et al (2009) Fluorescence as a potential

612 monitoring tool for recycled water systems: A review. Water Research 43:863-881

613 34. Baker A, Lamont-black J (2001) Fluorescence of Dissolved Organic Matter as a Natural

614 Tracer of Ground Water. Groundwater 39(5):745-750

615 35. Chen H, Liao Z, Gu X et al (2017) Anthropogenic Influences of Paved Runoff and 616 Sanitary Sewage on the Dissolved Organic Matter Quality of Wet Weather Overflows:

617 An Excitation-Emission Matrix Parallel Factor Analysis Assessment. Environ. Sci. 
619 36. Holbrook RD, Derose PC, Leigh SD et al (2006) Excitation-emission matrix 620 fluorescence spectroscopy for natural organic matter characterization: a quantitative 621 evaluation of calibration and spectral correction procedures. Applied Spectroscopy 60 $622 \quad(7), 791-799$

623 37. Ye Z (2012) Study on the correction of dry-weather pollutants inappropriate entry into 624 storm drainage based on pipe hydrodynamic model. Master Thesis, Tongji University, 625 Shanghai (in Chinese)

626 38. Hudson N, Baker A, Reynolds D et al (2007) Fluorescence Analysis of Dissolved 627 Organic Matter in Natural, Waste and Polluted Waters - A Review. River Research and $628 \quad$ Applications 23:631-649

629 39. S Sharifi, M M Haghshenas, T Deksissa et al (2014) Storm Water Pollution Source 630 Identification in Washington, DC, Using Bayesian Chemical Mass Balance Modeling, $631 \quad$ Journal of Environmental Engineering 140, 04013015

632 40. J A Vrugt (2016) Markov chain Monte Carlo simulation using the DREAM software 633 package: Theory, concepts, and MATLAB implementation, Environmental Modelling $634 \&$ Software $75,273-316$

635 41. Chen MF, Wu J, Lv YL et al (2008) Fluorescence Properties of Municipal Wastewater. 636 Acta Optica Sinica 28(3):578-582 (in Chinese)

637 42. Parlanti E, Worz K, Geoffroy L et al (2000) Dissolved organic matter fluorescence 638 spectroscopy as a tool to estimate biological activity in a coastal zone submitted to 639 anthropogenic inputs. Organic Geochemistry 31(12): 1765-1781

640 43. Ji GH (2015) Investigation of hydrophytes of slow flow water bodies to guide 
641 ecological restoration in Shanghai. Ph.D Dissertation, Tongji University, Shanghai (in 642 Chinese)

643 44. Ren BW, Zhao WH, Wang JT et al (2007) Three-Dimensional Fluorescence 644 Characteristic of Dissolved Organic Matter in Marine Mesocosm Experiment in 645 Jiaozhou Bay, China. Environmental Science 28(4):712-718 (in Chinese)

646 45. DM Reynolds (2002) The Differentiation of Biodegradable and Non-biodegradable

647 Dissolved Organic Matter in Wastewaters Using Fluorescence Spectroscopy. Journal 648 of Chemical Technology \& Biotechnology 77(8):965-972

649

650

651 


\section{Figures}

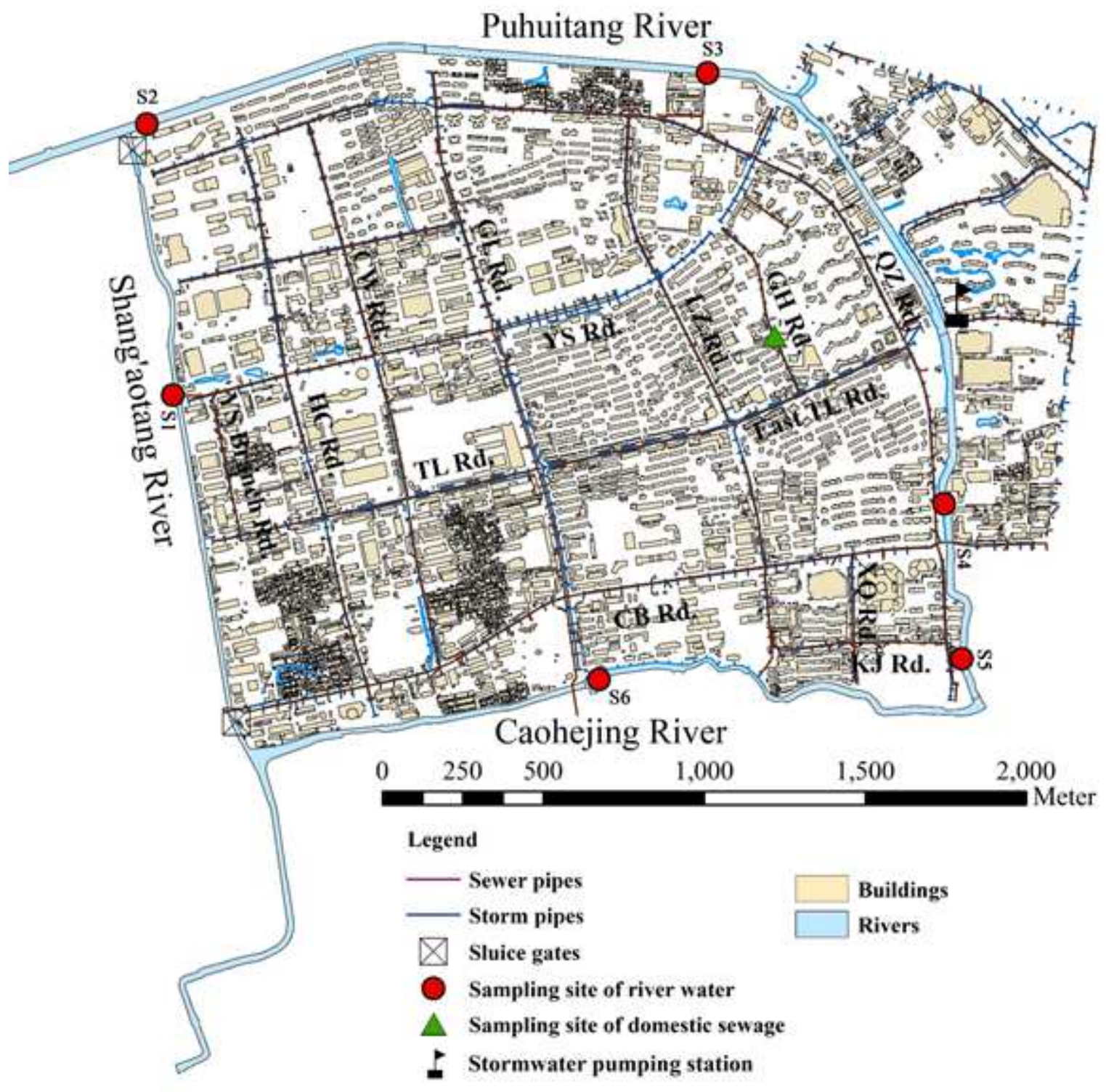

Figure 1

Study site description 

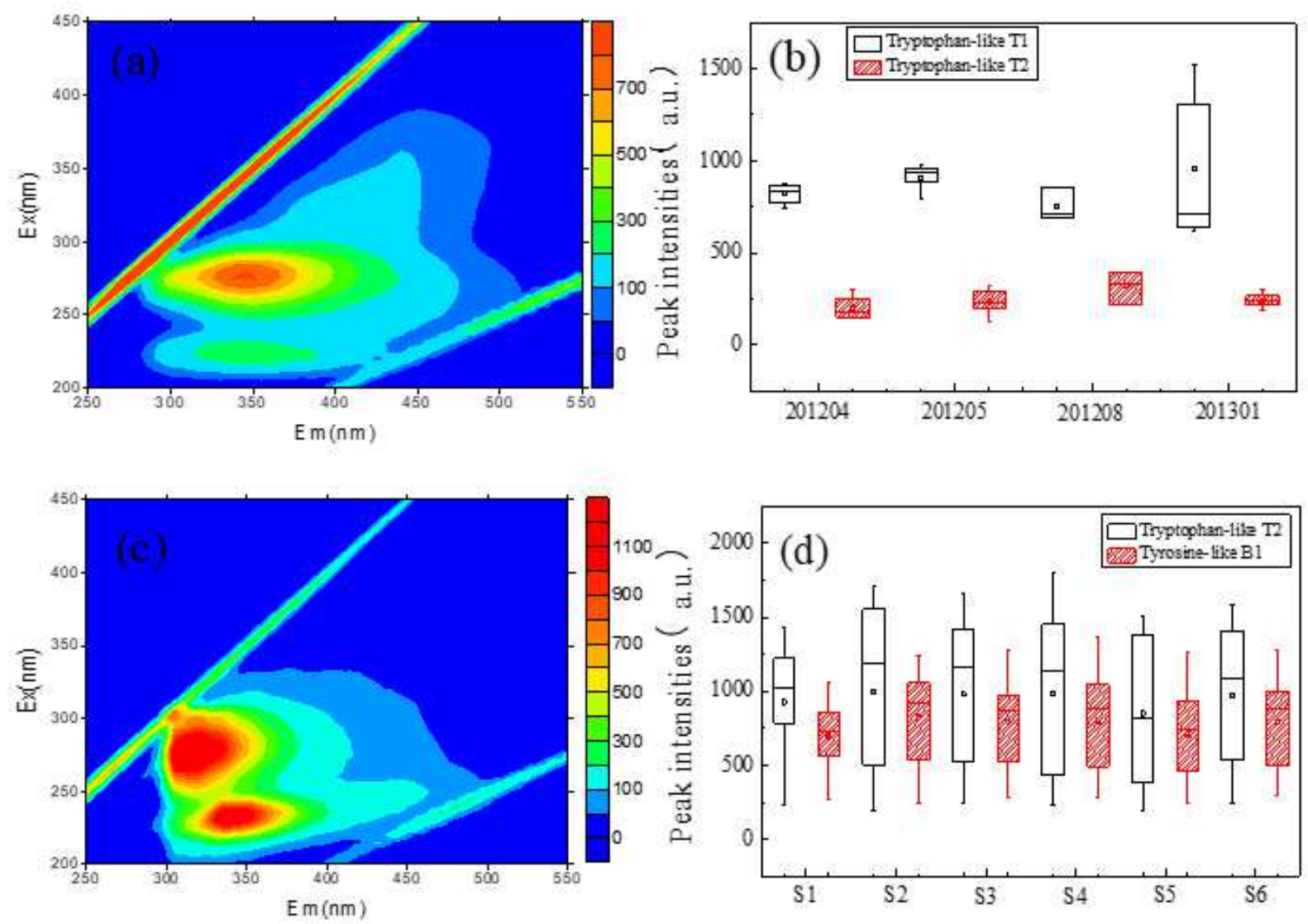

Figure 2

Detected EEMs for the domestic sewage and urban river water samples: (a) typical EEM of untreated domestic sewage; (b) fluorescent peak intensities of domestic sewage samples; (c) typical EEM of urban river water; (d) fluorescent peak intensities of urban river water at six sampling stations. 

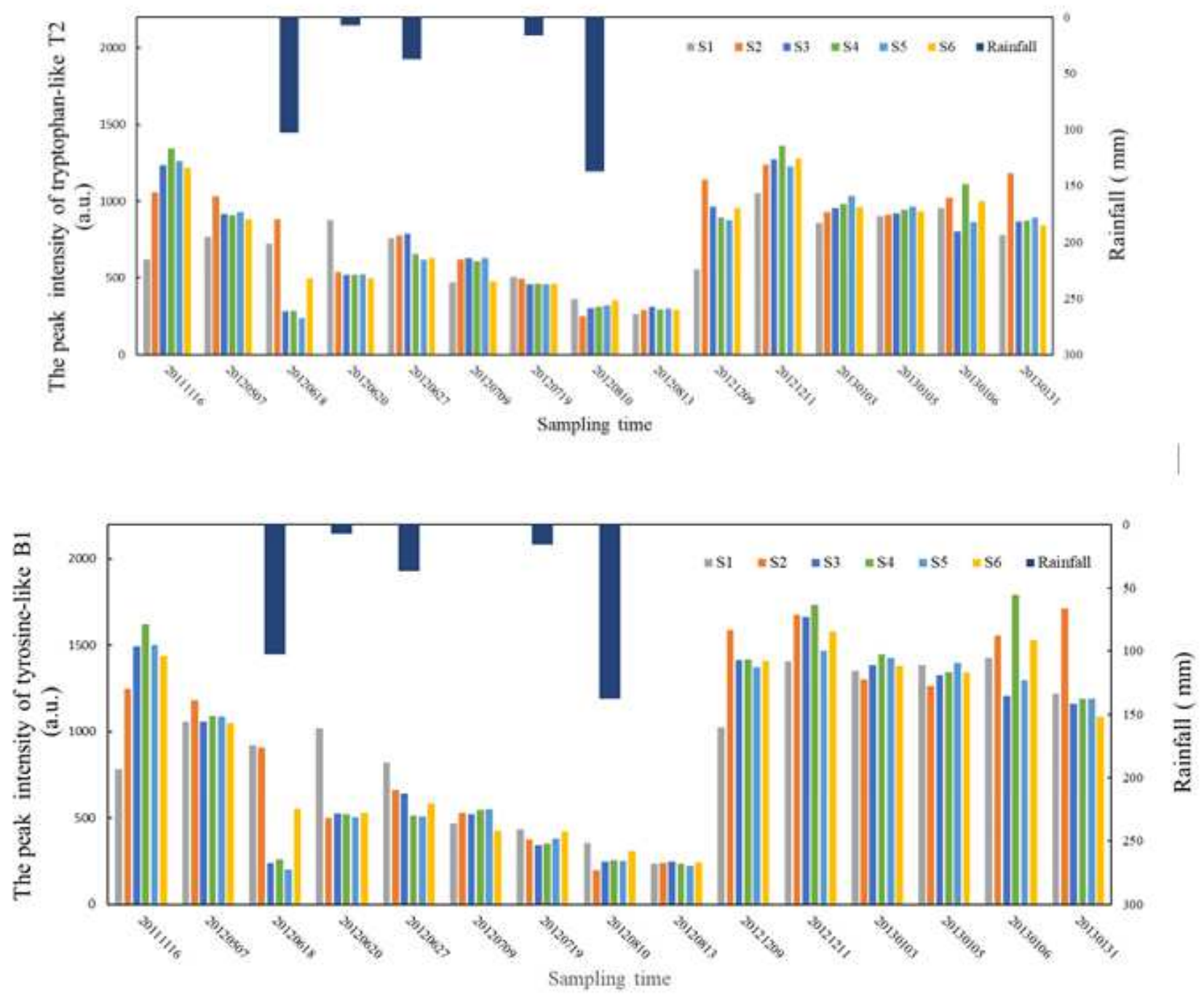

Figure 3

Detected fluorescence intensities at six sampling sites of the urban river water. 

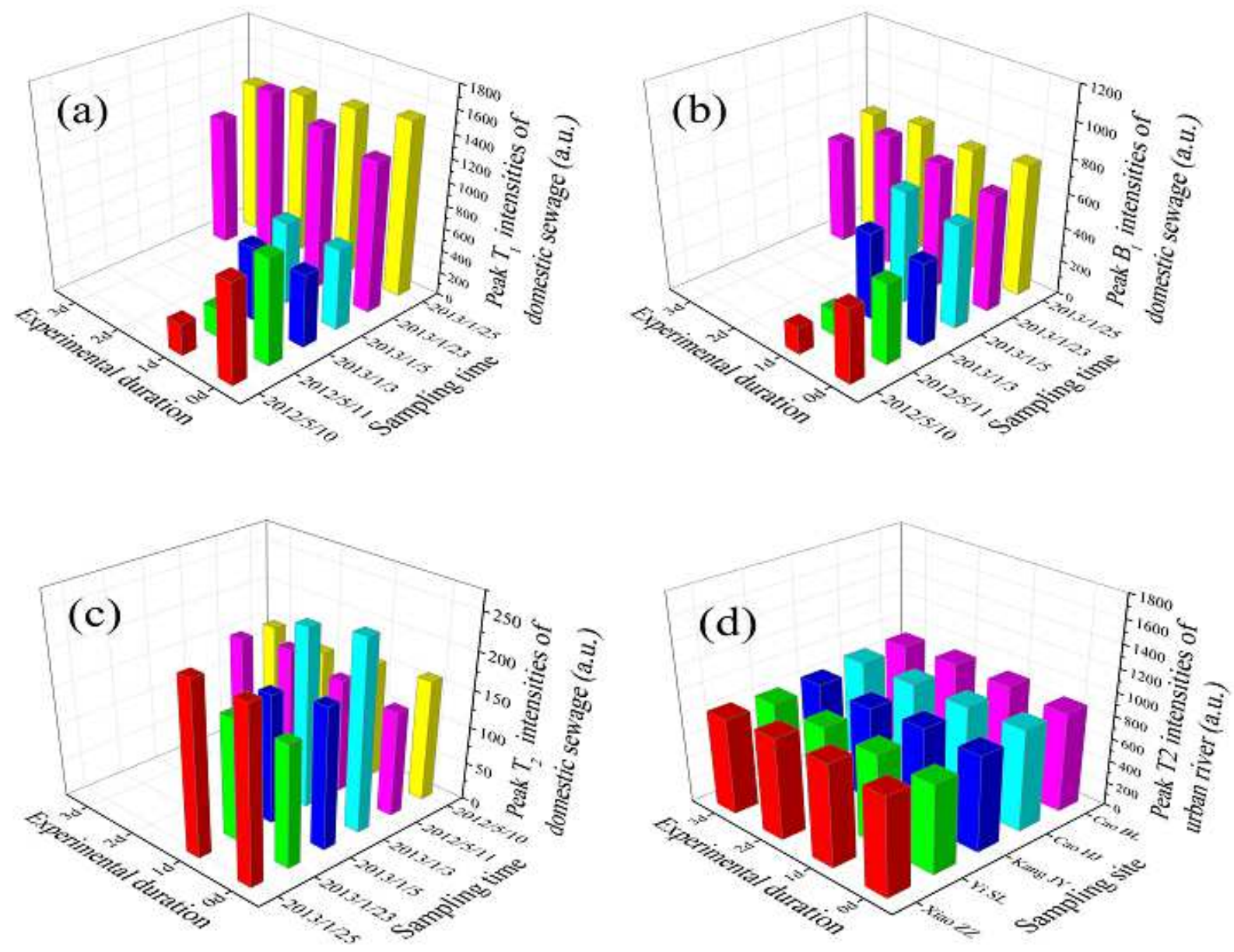

Figure 4

Changes of fluorescence peak intensities of domestic sewage and urban river water samples within the experimental duration. 


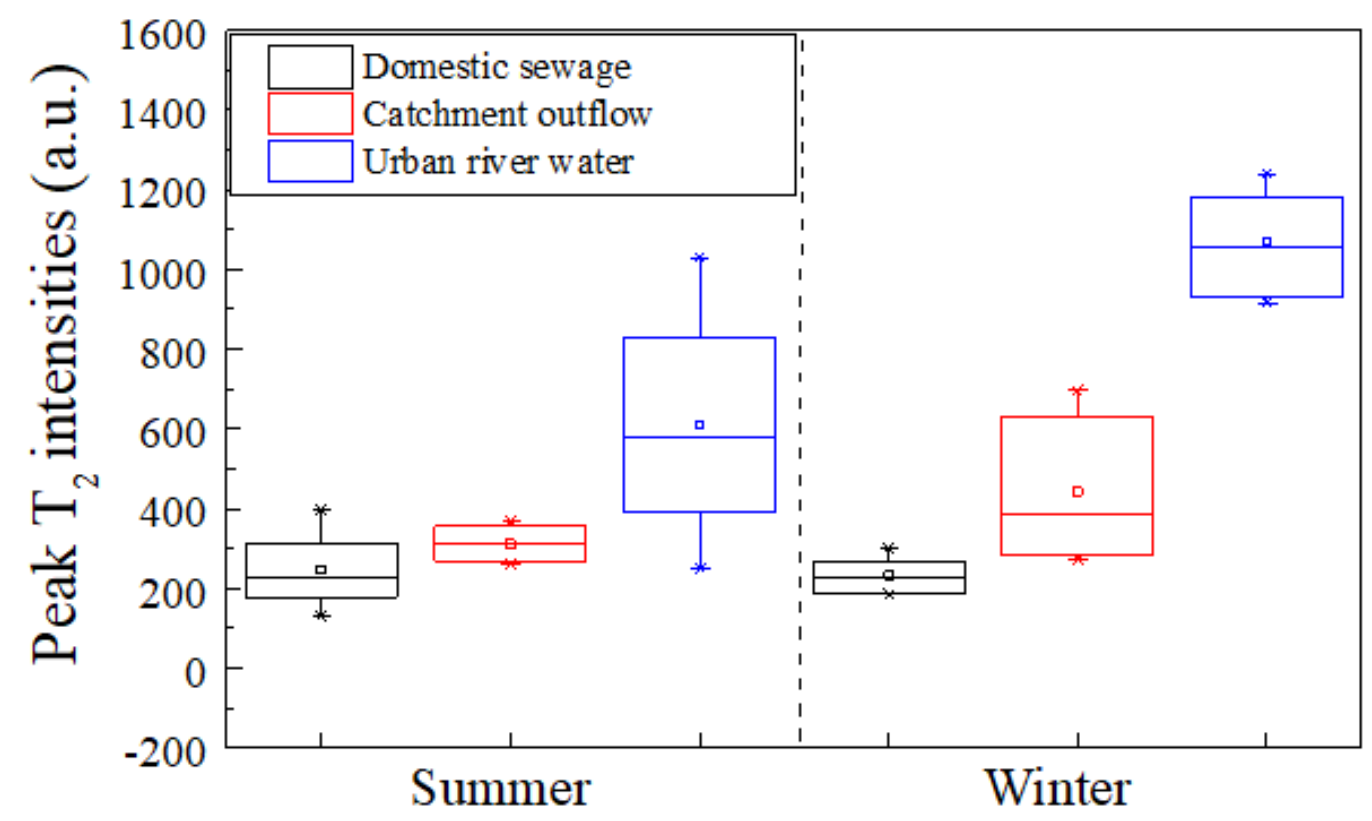

Figure 5

Comparison of fluorescence peak T2 intensities for the samples among river water, domestic sewage and catchment outflow.
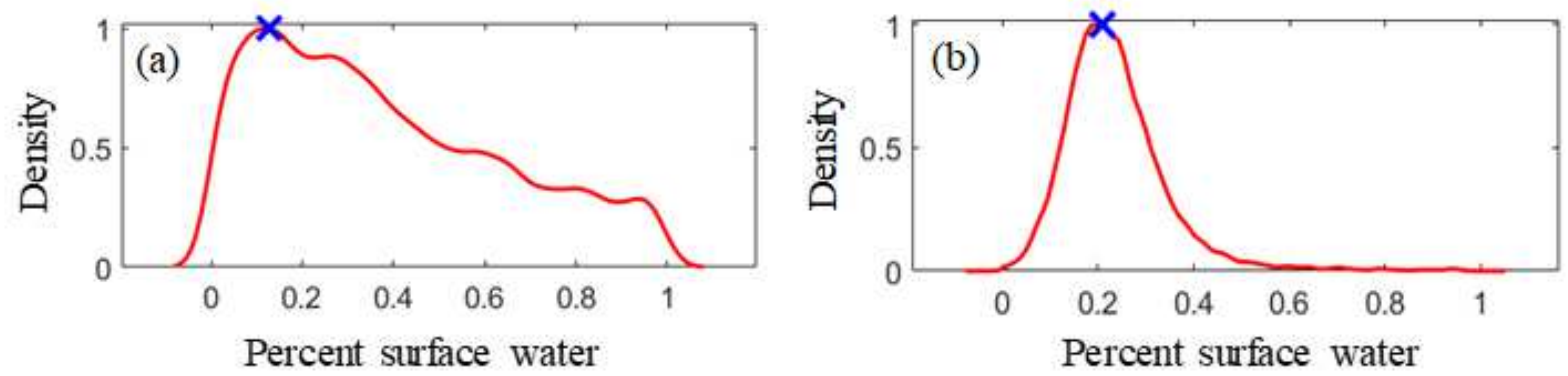

\section{Figure 6}

Maximum a posteriori probability (MAP) estimate for the percentage share of river water backflow into the storm drains on dry-weather days: (a) summer season; (b) winter season. 


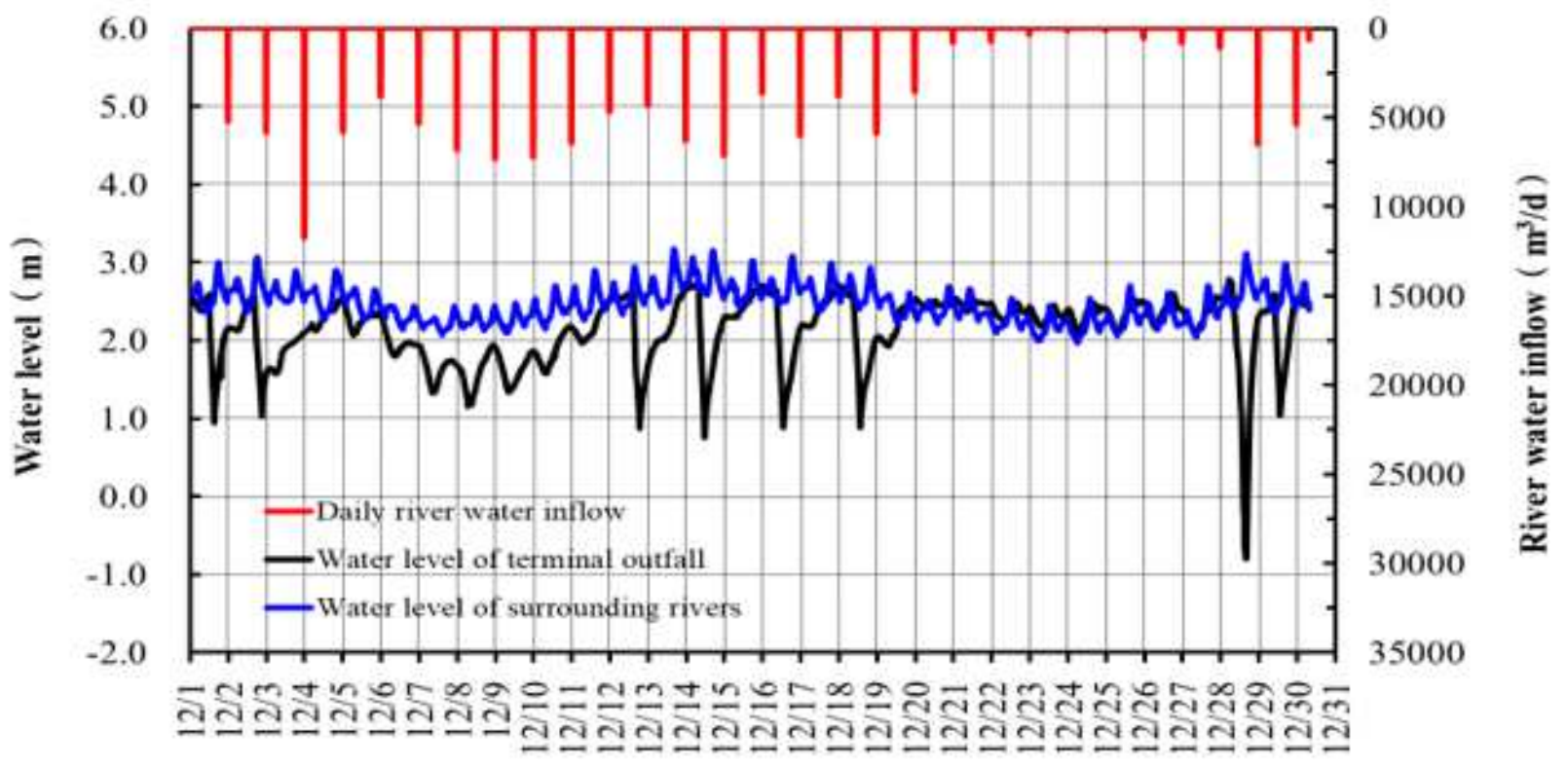

Figure 7

Estimated daily river water inflow into storm drains based on real-time water level between river and catchment outfall in winter season period.

\section{Supplementary Files}

This is a list of supplementary files associated with this preprint. Click to download.

- Supportinginformation.docx 